\title{
Research on the Implementation of New Tax Break for Micro and Small Companies
}

\author{
Xinliu Wei \\ School of Finance and Public Administration, Anhui University of Finance and Economics, Bengbu, China \\ Email: Xinliuwei@163.com
}

How to cite this paper: Wei, X. L. (2021) Research on the Implementation of New Tax Break for Micro and Small Companies. Open Journal of Social Sciences, 9, 316-324. https://doi.org/10.4236/jss.2021.96023

Received: June 1, 2021

Accepted: June 22, 2021

Published: June 25, 2021

Copyright (c) 2021 by author(s) and Scientific Research Publishing Inc. This work is licensed under the Creative Commons Attribution International License (CC BY 4.0). http://creativecommons.org/licenses/by/4.0/

\begin{abstract}
The development of micro and small companies has always been the focus of social attention. Due to the impact of the epidemic, the state has continuously issued a series of new tax policies, and the preferential strength for micro and small companies has increased unprecedentedly, which has effectively promoted the resumption and sustainable development of micro and small companies. Taking micro and small companies as the main research object, this paper investigates and analyzes the current situation of the implementation of the new tax break for micro and small companies, explores the existing problems, and puts forward effective suggestions for the implementation of the new tax break for micro and small companies, so as to promote the improvement of the new preferential tax policies for micro and small companies.
\end{abstract}

\section{Keywords}

Micro and Small Companies, New Tax Break, Implementation Plan

\section{Introduction}

Micro and small companies play a good role in promoting social and economic development. They can not only provide a large number of employment opportunities for the society, but also contribute far ahead to China's GDP. They are one of the important sources of national fiscal revenue. The outbreak of the epidemic has caused varying degrees of losses to micro and small companies in various industries, and the aggravation of business risks of micro and small companies has further increased the pressure of China's market economy.

At present, China's micro and small companies are mainly faced with the problems of tax burden and financing difficulties. The taxation of various links makes the operation cost of micro and small companies increase seriously, which makes the turnover of capital very difficult. Therefore, it is particularly 
important to help micro and small companies to alleviate the pressure of survival and reduce business risks through tax policy relief.

On March 31, 2021, in order to restore and support the development of micro and small companies, the State Council issued a new policy to further promote the development of micro and small companies. While increasing tax break for companies' income tax for micro and small companies, it also included individual businesses in the preferential policy, and the scope of preferential popularization was further expanded.

Through literature research, this paper analyzes the operation status and existing difficulties of micro and small companies under the implementation of the new tax break, and puts forward effective suggestions for the implementation of the tax policy of micro and small companies, in order to play an effective reference role for the tax reform of micro and small companies and promote the development of micro and small companies.

\section{Development Dilemma of Micro and Small Companies}

Micro and small companies play an important role in the market. In recent years, micro and small companies have created many jobs, which play a great role in promoting employment, improving people's livelihood and maintaining social stability. However, the replacement of micro and small companies is very frequent. The life span of most micro and small companies is only 3 to 4 years, and their viability and endurance are obviously insufficient. The main development difficulties of micro and small companies in the market are as follows:

\subsection{The Management System Is Not Perfect and the Survival Ability Is Weak}

Most micro and small companies mainly adopt family business model, and only a few choose to adopt modern business model. In this case, the companies often lack specialized and unified internal management system, professional management personnel and operation and management system, which leads to the obvious lack of observation and insight of micro and small companies on market development. In addition, the quality of operators is also uneven. The operators lack effective management experience, the capital and ability to support the sustainable development of the companies. They have a strong awareness of following suit when choosing, and are more likely to lead to vicious competition. As a result, the survival ability of micro and small companies is very weak.

\subsection{Lack of Information Management, and Exist Market Information Asymmetry}

The direction of market operation is mostly controlled by large and medium-sized companies, which have relatively perfect operation and management system, strong financial support and good operation team. Under the background of "Internet plus", most large and medium companies have actively applied Enterprise Resource Planning and digital management to the actual man- 
agement of companies. Relying on big data, large and medium-sized companies have grasped the market dynamics more quickly and accurately, and greatly promoted their economic benefits.

The awareness and ability of information management of micro and small companies are relatively weak. Firstly, there is a lack of Informatization Talents in micro and small companies. Secondly, the financial ability of micro and small companies cannot support the construction and operation of companies information platform. Therefore, to a large extent, this has caused great obstacles for micro and small companies to realize information management. As a result, the products of micro and small companies not only have a weak voice in the market economy, but also are in the state of asymmetric information. It is difficult for them to grasp the opportunity to develop rapidly, and it is also difficult to create a broader way of operation in the industry and enhance their brand influence.

\section{The Current Situation of the Implementation of the New Tax Break Policies-Taking Province $A$ as an Example \\ 3.1. Profit Growth Rate of Micro and Small Companies Turns Positive}

At the beginning of 2020, due to the impact of the epidemic, the profits of many micro and small companies decreased significantly. After the introduction of the new tax policies, according to the statistics of the Statistics Bureau of province A, the growth rate of the total profits of non-public industries in the first three quarters of 2020 changed from negative to positive. Among them, the total profits of large and medium-sized companies decreased by $14.5 \%$, while the total profits of micro and small companies increased by $6.2 \%$, This is also the first growth since 2020 (Statistics Bureau of Guangxi Zhuang Autonomous Region, 2020). In addition, with the support of tax break policies, many companies said that have more confidence in resolving the difficulties of the epidemic, and have more abundant funds and stronger development potential.

\subsection{Tax Reduction and Exemption Will Directly Benefit Companies and Greatly Reduce the Burden of Micro and Small Companies}

In 2020, the tax revenue of province A will be 227.65 billion yuan, the new Tax reduction and exemption will be over 17 billion yuan, and the deferred tax payment will be 9.25 billion yuan, which will greatly reduce the business burden of companies (Statistics Bureau of Guangxi Zhuang Autonomous Region, 2020). Among them, as of November 2020, 20,933 new tax payers have been registered in city B of province A, with a year-on-year gross of 3534, an increase of $20.31 \%$. The confidence of market players has been continuously improved, and the economic operation has been steadily improving. In addition, according to the data of the State Administration of Taxation of city B, the tax to be paid per 100 yuan of annual revenues decreased from 6.64 yuan in 2019 to 5.54 yuan in 2020, 
a decrease of 20.32\%; The R \& D (research and development) investment of companies was 489 million yuan, with a year-on-year gross of $18.4 \%$ (State Administration of Taxation Guangxi Zhuang Autonomous Region Taxation Bureau, 2021).

Thus it can be seen that the implementation of the new tax break has greatly reduced the operating costs of small and medium-sized companies. At the same time, it has promoted the technological upgrading of small and medium-sized companies and accelerated the development and innovation of them.

\subsection{Continue to Deepen the "Bank-Tax Interaction" to Solve the Financial Problem}

Since 2020, the tax bureau of province A has continued to deepen the "Bank-Tax Interaction", actively built an information platform and cooperated with the banking department to improve the "export rebate loan", "tax preferential loan" and other products, so as to help the micro and small companies who pay taxes in good faith to further solve the financing problem and reduce the burden of the development of micro and small companies. According to the latest data of the tax bureau of province A, in 2020, province A will additional issue 87.36 billion yuan of "Bank-Tax Interaction" loans, which will solve the capital problem for 61400 micro and small companies, and makes the small and micro enterprises resume work and economic recovery stable (State Administration of Taxation Guangxi Zhuang Autonomous Region Taxation Bureau, 2020). At the same time, the improvement of "Bank-Tax Interaction" products also plays a good role in publicizing and promoting Credibility Taxpaying, which is an effective way to encourage and support Credibility Taxpaying.

\section{Existing Problems of New Tax Policies for Micro and Small Companies}

\subsection{The Publicity of the New Tax Policy Is Insufficient, and the Effect of Helping Micro and Small Companies Is Limited}

Although the introduction of tax related preferential policies such as "tax break" and "Bank-Tax Interaction" has made the overall situation of capital turnover of micro and small companies continue to improve, many micro and small companies are still facing capital and financing problems. The main reasons why the capital problem of micro and small companies cannot be solved are as follows:

Firstly, micro and small companies have their own problems. Some companies have weak points in their own system, operation mode, fund management and application, such as the lack of specialized and unified internal management system, professional tax personnel and operation management system, which leads to the non-standard tax operation process of micro and small companies and makes them unable to enjoy preferential policies or solve the problems even if they enjoy the policies; Secondly, the publicity of the new tax policies by the relevant tax departments is still insufficient, especially for the local preferential tax policies, such as the "Bank-Tax Interaction", which are not issued by the 
state but jointly launched by the tax departments and other parties, the communication strength is obviously lower than the national laws and regulations. Many micro and small companies do not know the policy of "Bank-Tax Interaction", so that they are not enthusiastic to participate. The above two reasons lead to the lack of the actual conversion rate of the new tax policy, which limits the help of the new policy to micro and small companies.

\subsection{There Are Still Limitations in the Administration of Tax Collection}

At present, for the management of micro and small companies, China has not formed a series of efficient collection and management mode. First of all, the qualification of micro and small companies is relatively complex, and they need to be recognized by relevant departments to enjoy tax preferences. Due to the small scale and lack of funds, the ability of micro and small companies to employ professional tax or accounting personnel is always limited. Many micro and small companies believe that it takes a lot of time and manpower to prepare a lot of financial information to declare tax preference, but after obtaining the qualification, they can enjoy limited tax preference. Therefore, micro and small companies usually choose to give up the application for tax preference ( $\mathrm{Li} \& \mathrm{Li}$, 2021).

Secondly, the current tax system still has the phenomenon of information asymmetry, there may be many inaccuracies in the information declared by micro and small companies, and the current tax system lacks the management of information data of micro and small companies. With the continuous increase of the number of micro and small companies, the number of tax paying companies and tax amount also increase correspondingly. If the tax system only focuses on large companies which is the large tax sources, it is easy to ignore the tax declaration of micro and small companies, resulting in tax loss.

\subsection{Preferential Tax Policies Change Frequently, and Micro and Small Companies Are Not Sensitive to Them}

For micro and small companies with small total assets, their profit space is relatively narrow, but the absolute value of their tax burden is not small. Therefore, compared with the ability to pay micro and small companies, tax has become a heavy burden in the operation of micro and small companies.

At present, most of the preferential tax policies in China are temporary preferential policies, some of which last only three years or even shorter. They are mainly used for some emergency purposes, with short duration and great variability, and lack of a complete and standardized policy system. However, most of the micro and small companies are unable to spend a certain amount of manpower and financial resources to study the new tax policy every other period of time, so the participation of micro and small companies in the new tax policy will inevitably be greatly reduced. In the case of quick replacement and frequent supplement of preferential tax policies, micro and small companies lack profes- 
sional operation and management are not sensitive to the change of tax reduction policies, and there will be a certain time lag in their response to the relevant tax preferential measures.

In addition, due to the frequent updating of tax preferential policies, there is a certain degree of incoherence between policies, micro and small companies lacking professional tax or financial departments are not able to deal with financial problems, and they will be tied up in the application of preferential tax policies, resulting in the effect of preferential tax policies cannot reach the expected value. Zhang Mingtao also pointed out in the article "Research on the implementation of preferential tax policies for micro and small companies in city $\mathrm{Q}$ of Shandong Province", that frequent adjustment of tax policies for micro and small companies will cause short-sighted behavior in the development process of micro and small companies, which cannot effectively drive and guide micro and small companies to invest and finance, and is not conducive to the long-term development of companies. Therefore, the coordination and convergence of relevant policies is very important (Zhang, 2020).

\section{Suggestions on Optimizing the Implementation of the New Tax Policy for Micro and Small Companies}

\subsection{Increase Publicity Efforts and Take the Initiative to Help Apply for Tax Break}

In view of the low awareness and participation of micro and small companies in the new tax policies, the grass-roots tax authorities are the tax authorities closest to taxpayers. They should further play the role of publicity and guidance. While handling tax affairs for micro and small companies, they should actively introduce and guide micro and small companies taxpayers to understand and choose relevant new policies, and make professional interpretation of relevant policies. At the same time, it also puts forward higher requirements for the tax professionalism of grass-roots tax personnel.

In addition, the publicity enthusiasm of the relevant tax personnel is not high, which is one of the reasons for the low awareness and participation of micro and small companies in the new tax policy. Tax departments can set up relevant incentive policies to encourage tax personnel to actively publicize and guide micro and small companies that eligible but have not applied for relevant tax preference, so as to create a good policy environment, which can bring good help to micro and small companies or the effective implementation of policies.

\subsection{Establish a Long-Term Tax Mechanism for Micro and Small Companies}

First of all, we should correctly understand the effect of tax preference for micro and small companies. The tax preference for micro and small companies cannot be regarded as a loss of tax revenue. Micro and small companies occupy most of the companies in China, which play a great role in national economic development and social stability. At the same time, micro and small companies are also 
the fundamental foundation for the development of large and medium-sized companies. Therefore, the tax preference for micro and small companies is to help micro and small companies grow into large and medium-sized companies, so as to promote social and economic development and bring more tax revenue to the country.

In order to benefit micro and small companies more widely, tax policies need to establish a long-term tax mechanism. Formulate special and long-term effective tax policies according to the development characteristics and special circumstances of micro and small companies, rather than temporary policies only for a special period. Only long-term and stable assistance can truly benefit all micro and small companies and enable them to grow and develop in a stable and powerful environment. After the epidemic, it will lead to the change of industrial structure and rebound of consumer demand, so as to further expand the double development space of endogenous supply and demand in the economic system. Through continuous preferential policies and a new round of innovation, it will effectively stimulate the vitality and competitiveness of emerging markets (Wan et al., 2020).

\subsection{Promote the Development of "Micro and Small Companies Tax Service" Market}

The more tax system can promote tax fairness and take into account the interests of all stratum, the higher the requirement of information declaration will be. With the reform and development of individual income tax, the demand of "Individual Income Tax Service" market is gradually expanding. With the increasing number of micro and small companies and the increasing social demand for micro and small companies, the state has correspondingly launched a number of tax policies for micro and small companies, and the demand for "Micro and Small Companies Tax Service" market will gradually increase. The government should take relevant measures to promote the development of the "Micro and Small Companies Tax Service" market. Through professional knowledge and tax service, the Tax Service can help micro and small companies correctly declare relevant preferential tax policies and promote the development of tax related products such as "Bank-Tax Interaction", so as to further help micro and small companies achieve tax break and reduce their economic burden. When the new policy is promulgated, the "Micro and Small Companies Tax Service" market should play a guiding role and effectively guide qualified micro and small companies to apply in time. This service can not only improve the enthusiasm of micro and small companies to participate, but also further reduce the burden of publicizing and inspection of tax departments, and improve the efficiency of the administration of tax collection.

\subsection{Improve the Information Platform of Micro and Small Companies}

Improve the information platform of micro and small companies, can ensure the 
authenticity, integrity and standardization of the registration information of micro and small companies, so that the government and other relevant departments can better grasp the real information and operation status of micro and small companies. Through the improvement of the information platform, firstly, it can as far as possible to avoid the situation that micro and small companies have incomplete material preparation or partial material loss when they declare tax preferential policies. Complete companies information records can reduce the further time and manpower for micro and small companies to declare tax preferences, and provide convenience for micro and small companies to declare tax preferences; Secondly, when the new policy is promulgated, micro and small companies that may meet the application conditions can be initially identified through big data information screening. Tax personnel can publicize and guide these companies through SMS, telephone and other means, so as to improve the implementation process and system of the new tax policy and strengthen the enthusiasm of micro and small companies to participate in the new tax policy; Thirdly, the improvement of micro and small companies information helps government departments to master the detailed situation and credit information of micro and small companies, so as to further promote the cooperation between tax and finance, and provide support for micro and small companies loans with good credit information. With the policy support or guarantee of the government, micro and small companies will be able to obtain loans more quickly and conveniently, and develop healthily and continuously.

\section{Conclusion}

Since the outbreak of the epidemic, the state has repeatedly increased the tax break for micro and small companies, injecting a lot of vitality into them. However, in order to further ensure that the preferential tax policies can reach micro and small companies, we should further take a series of specific measures, collect the needs and opinions of micro and small companies in time, and carry out more comprehensive and powerful policy guidance according to the specific needs, so as to ensure that micro and small companies should know and enjoy the relevant tax policies. Only in this way can we continuously stimulate the development vitality of micro and small companies and add new momentum to the development of market economy.

This paper only combines the new tax policy of micro and small companies with the relevant financial statistics, and in view of the existing problems puts forward some suggestions to optimize the implementation of the new tax policy. However, the specific and executable implementation plan still needs to be further studied in combination with the actual development situation of micro and small companies and the specific situation of different regions.

\section{Conflicts of Interest}

The author declares no conflicts of interest regarding the publication of this paper. 


\section{References}

Li, J., \& Li, P. (2021). Research on Preferential Tax Policies for Micro and Small Companies under the New Economic Normal. Marketing Circles, No. 18, 171-172

State Administration of Taxation Guangxi Zhuang Autonomous Region Taxation Bureau (2021). “Tax Power” Makes Great Contributions - Yulin City Reduces Taxes and Fees to Help Return to Production.

State Administration of Taxation Guangxi Zhuang Autonomous Region Taxation Bureau (2020). Guangxi Taxation Bureau Actively Promotes "Bank Tax Interaction" to Solve Enterprise Financing Problems.

Statistics Bureau of Guangxi Zhuang Autonomous Region (2020). Guangxi Statistical Yearbook. Beijing: China Statistics Press.

Wan, X. Y. et al. (2020). COVID-19, The Impact of Tax Reduction and Tax Reduction Policy on Small and Micro Businesses: Based on the Analysis of Micro Simulation. The Analysis Price Theory and Practice, No. 1, 27-33.

Zhang, M. (2020). Research on the Implementation of Preferential Tax Policies for Micro and Small Companies in Q City of Shandong. Postgraduate Thesis, Qingdao: Shandong University of Science and Technology. 